\title{
La adquisición de la escisión en el español peninsular
}

Carlos Felipe da Conceição Pinto (Doctorando UNICAMP)

\section{Resumen}

Teniendo en cuenta la variación de la escisión en el español actual, este trabajo pretende investigar cómo los niños españoles adquieren esas construcciones. La pregunta principal del texto es si los niños españoles producen inicialmente las construcciones inexistentes en la variedad europea adulta y enseguida las pierden o si esos niños nunca producen esas construcciones. Se analizaron 18 niños entre 2 y 10 años de edad (2 niños para cada franja de edad) a partir del corpus CHILDES. Los dados mostraron que los niños producen construcciones inexistentes en la gramática adulta, siendo que una de esas construcciones sólo aparece en el niño de 3 años y la otra permanece en todas las edades. La interpretación de los datos es la de que no hay, en principio, un problema de adquisición del lenguaje, pero variación en el español ya que se encuentran las construcciones consideradas inexistentes en diversos estudios en el habla de los adultos en la interacción con los niños.

Palabras-clave: Escisión; variación del español; sintaxis del español europeo. 


\section{Introducción ${ }^{1}$}

Diversos estudios recientes vienen mostrando que la escisión

Agradezco muchísimo a Ruth Lopes, a Mary Kato y a Sergio Menuzzi por los comentaintentado hacer todas las correcciones que me han sugerido. Sin embargo, todos los errores y problemas que persistan son de mi total responsabilidad.

2 El español de España también presenta ese tipo de construcción.

3 El texto de Pagotto (1998) discute el cambio en la norma culta brasileña en el siglo XIX a partir del cambio por el que pasó el portugués europeo en este período. Sin embargo, se puede llevar la idea central de Pagotto (1998) a casos de otras lenguas, principalmente al caso del español, una lengua tan semejante y cercana geográficamente, con historia parecida y con centro legislador (la RAE) muy fuerte.

4 Di Tullio (1999, p. 6), al analizar las hendidas dice:

La sanción que ha recaído sobre esta forma a partir de Bello ("crudo galicismo, con que se saborean algunos escritores sur-americanos", párrafo 812) desconoce su extensión panrománica, así como sus antecedentes estrictamente hispánicos. Lejos de toda intención de polemizar en el terreno de la normativa, podemos explicar su aparición y extensión, sin apelar al préstamo -retomando la interesante observación de Pedro Henríquez Ureña de que su uso no aparecer restringido a sectores que mantenían un contacto asiduo con el francés.

${ }^{A}$ partir de ese fragmento, se puede imaginar que ya en el siglo XIX estas construcciones sonaban raras al patrón lingüístico europeo, lo que sugiere que el cambio ocurrió entre los siglos XVII y XVIII.

no se presenta uniformemente en todo el mundo hispánico. Por ejemplo, Moreno Cabrera (1999), Di Tullio (2005) y Pinto (2008) muestran que el español peninsular sólo presenta las llamadas construcciones seudo-hendidas (wh-cleft) como se ilustra en (2). Por otro lado, algunas variedades del español americano presentan, además de las seudo-hendidas, las hendidas (it-clef) como se ilustra en (3) y las seudo-hendidas reducidas como en (4).

(1) Todos hablan de María.
a. RÍA

b. DE MARÍA es de quien todos hablan.
c. Es DE MARÍA de quien todos hablan.

(3) a. Es DE MARÍA que todos hablan.

b. DE MARÍA es que todos hablan.

c. DE MARÍA que todos hablan².

$$
\begin{aligned}
& \text { Todos hablan es } \\
& \text { DE MARÍA. }
\end{aligned}
$$

Oración neutra (no-marcada)

Seudo-hendida Básica (SB)

Seudo-hendida

Inversa (SI)

Seudo-hendida

Extrapuesta (SE)

Hendida Básica

(HB)

Hendida Inversa

(HI)

Hendida sin cópula (HSC)

\section{Seudo-hendida \\ Reducida (SR)}

En este trabajo, pretendo mostrar cómo los niños adquieren las construcciones de escisión en el español europeo. Teniendo en cuenta que el español peninsular es la variedad que presenta menos construcciones de escisión y el hecho de que diversos estudios sobre la adquisición del lenguaje muestran que los niños producen construcciones inexistentes en las gramáticas de las generaciones adultas, la pregunta que hago es si los niños europeos producen las construcciones de escisión ilustradas en (3) y enseguida las pierden o si nunca adquieren tales construcciones.

Moreno Cabrera (1999) señala, a partir de ejemplos de Lope de Vega, que las construcciones en (3) eran posibles en el español de los Siglos de Oro (siglos XVI y XVII). Siguiendo la línea de pensamiento de Pagotto (1998) ${ }^{3}$, de que la norma culta también puede provocar innovaciones (al contrario de lo que se piensa siempre, que es la norma popular la que innova), se puede suponer que el español peninsular culto sufrió cambios lingüísticos ${ }^{4}$ mientras que la norma popular (que no está descrita 
adecuadamente) conserva características de tiempos pasados ${ }^{5} \mathrm{y}$, por esa razón, los niños podrían presentar tales construcciones que no aparecen en el español europeo adulto culto, ya que la norma popular es la que les sirve de input a esos niños.

\section{La escisión}

\subsection{Definición}

Modesto (2001, p. 21) define la escisión como:

(5) As construções clivadas são sentenças especificacionais em que um movimento A-barra dispara leituras características de contraste, exclusividade e exaustividade.

De esta manera, una oración como la de (6) tendrá dos lecturas semánticas posibles, como se ilustra en (7) y (8):

(6) La que ha venido ha sido mi mujer. (MORENO CABRERA, 1999, p. 4291)

(7) Lectura especificacional: Mi mujer ha venido.

(8) Lectura predicacional: La mujer que ha venido ya no es mi mujer.

Sólo las construcciones que tengan la lectura del ejemplo (7) pueden considerarse construcciones de escisión, teniendo en cuenta que el valor de verdad de una construcción de escisión debe ser equivalente al valor de verdad de una oración no-marcada, como ilustrado en los ejemplos (1-4).

partir de la definición en (5), Modesto (2001) hace una redefinición de lo que son construcciones de escisión. Por ejemplo, al considerar oraciones como

(9) A Suzanita é quem quer casar. (MODESTO, 2001, p. 21)

(10) A conta pago eu. (MODESTO, 2001, p. 22)

5 En este sentido, una posibilidad es la de que la variedad innovadora no sea el español caribeño, por ejemplo, pero propio el español europeo. Por otro lado, se puede suponer que las construcciones de escisión del español caribeño de hoy sean posibles por motivos diferentes de las construcciones del español europeo de los Siglos de Oro.

6 Para Modesto (2001), la interpretación de (9) es "A Suzanita é a casadoira".
Modesto (2001) saca (9) del grupo de las construcciones de escisión porque no tiene la lectura característica ${ }^{6}$ aunque superficialmente se parece a una hendida e incluye (10) en el grupo de las construcciones de escisión porque, aunque no tiene la estructura con SER X QUE, dispara un movimiento A-Barra y tiene la interpretación característica de la escisión. Sin embargo, sólo considero como construcción de escisión aquellas construcciones que tengan, a la vez, una estructura sintáctica y una interpretación semántica específica de escisión. Por lo tanto, ni (9) ni (10), en mi análisis, son construcciones de escisión.

Un segundo punto que hay que poner de relieve es la distinción que Modesto (2001) hace entre hendidas y seudo-hendidas, que, en su opinión, no presentan la misma estructura aunque 
tengan lecturas semánticas idénticas. Las construcciones hendidas se constituyen de dos oraciones bipartidas cada cual con su verbo; por otro lado, las construcciones seudo-hendidas se constituyen de una oración copulativa en la que una oración relativa libre ocupa la posición de predicado, que selecciona un sujeto que satisface el valor de la variable de la relativa libre.

En ambas construcciones se propone la siguiente estructura:

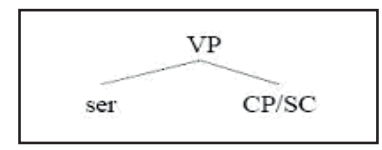

La diferencia entre las dos, en otras palabras, es que, en la hendida, el VP selecciona una oración completa e independiente $(\mathrm{CP})$; ya en la seudo-hendida, el VP selecciona una oración pequeña, que sólo se constituye oración si contiene la cópula.

\subsection{Los usos discursivos}

Aunque las oraciones en (12a) y (12b) a continuación tengan la misma estructura sintáctica y semántica, la diferencia entre ellas estriba en lo que el hablante asume como información nueva e información conocida en el discurso:

(12) a. Hoy por la mañana él se levantó tarde.

b. Él se levantó tarde hoy por la mañana.

Zubizarreta (1998) define la noción de foco a partir de la noción de presuposición: el foco es la parte no-presupuesta y la presuposición es la información compartida por el hablante y el oyente en el momento en que se emite un discurso dado.

En relación con el tipo semántico del foco, Zubizarreta (1998, 1999) propone una distinción entre foco informativo por un lado y foco contrastivo y enfático por otro. El foco informativo es el elemento que atribuye un valor a una variable a través como en (13):

A: ¿Quién comió el pastel?

B: El pastel, lo comió Juan.

Por otro lado, el foco contrastivo va a negar una aserción previa y hace una nueva aserción; y el foco enfático va a confirmar una aserción previa. Zubizarreta $(1998,1999)$ considera el foco contrastivo y el foco enfático estructuralmente idénticos. El ejemplo (14a) indica un foco contrastivo y el ejemplo (14b) ilustra el foco enfático.

(14) a. Hablante 1: ¿Quieres este libro?

Hablante 2: No... Quiero EL OTRO.

b. Hablante 1: ¿Quieres este libro?

Hablante 2: Sí... Quiero ESE MISMO. 
Zubizarreta $(1998,1999)$ dice que, en muchas lenguas, la prominencia prosódica juega un papel fundamental en la identificación del foco y distingue dos tipos de acentos nucleares: el acento nuclear neutro y el acento nuclear enfático o contrastivo y dice que, en español, el acento nuclear neutro se pone en la palabra o constituyente más encajado del grupo melódico:

El gato se comió un ratón. (ZUBIZARRETA, 1999, p. 4229)

Sin embargo, si se pone el acento nuclear en otra posición, que no la última palabra o constituyente del grupo melódico, se tendrá una interpretación enfática o contrastiva:

(16) El gato comió un ratón. (ZUBIZARRETA, 1999, p. 4229)

Así, como el español requiere que el acento nuclear neutro, el que identifica el foco informativo, esté en la posición más encajada, conforme las reglas prosódicas propuestas por Zubizarreta (1998), la prosodia implicará alteraciones sintácticas con la finalidad de satisfacer dicho requerimiento, cuando se quiera responder a una pregunta como "¿Quién comió el pastel?"7.

\subsection{La variación de la escisión en el español actual}

Como comenté en la introducción, la distribución de las construcciones de escisión no es uniforme en todo el mundo hispánico. Moreno Cabrera (1999) y Di Tullio (2005) dicen que (3a) y (3b) son exclusivas del español americano. Di Tullio (2005, p. 5) dice que "[a]mbos, el español europeo y el español americano poseen las seudo-hendidas. Hasta el momento, sólo el español americano tiene las reales hendidas, que son rechazadas por los gramáticos normativos" ${ }^{\prime \prime}$. Respecto de (4) los autores muestran que son específicas del español del Caribe.

En Pinto (2008) estudié las estrategias de focalización en cuatro variedades del español (México, Argentina, España y Cuba) y muestra que: a) las hendidas, como ilustradas en (3) son posibles en Argentina y Cuba; b) no registra casos de SR, como en (4) en el corpus que analizó; c) (3c) es posible en México y España9.

Por otro lado, en Pinto $(2008,2010)$ analizo ambas construcciones en (2c) y (3a) como hendidas básicas, con la misma estructura. Propongo que haya alguna diferencia en los rasgos de foco del CP subordinado entre el español europeo y algunas variedades del español de América. La propuesta general es la de que hay un rasgo [ \pm concordancia] entre el especificador y el núcleo de CP, en el sentido de Rizzi (1991), que es lo que distingue las lenguas humanas en lo tocante a la variación entre las hendidas básicas y las seudo-hendidas extrapuestas. Así, cuando el XP[+foco] se mueve de su posición inicial dentro de IP para SpecCP puede desencadenar o no concordancia con el núcleo $\mathrm{C}^{\circ}$. Cuando hay concordancia, se deriva una seudo-hendida extrapuesta; cuando no hay concordancia, se deriva una hendida básica. 
Si hay evidencias para analizar (2c) como una verdadera hendida, cuya estructura es idéntica a (3a), tal análisis pone un problema a la hipótesis de que el español peninsular no tiene las verdaderas hendidas si se consideran las hendidas inversas como en $(3 b)^{10}$. Sin embargo, si considera el trabajo de Kato y Ribeiro (2009), quienes proponen que la hendida inversa no deriva de la hendida básica. Es decir, aunque se analice la construcción en (2c) como una verdadera hendida con concordancia dinámica en el núcleo $\mathrm{C}^{\circ}$, el problema de que el español europeo tenga ese tipo de construcción pero no tenga construcciones como (3b) queda resuelto porque (2c) y (3b), aunque hendidas, no tienen la misma derivación. Además, en ( $3 \mathrm{~b})$, el CP subordinado tiene el rasgo [-foco], por ende, la discusión del rasgo [ \pm concordancia] no se aplica a dicha construcción, ya que tal rasgo sólo estaría presente en un $\mathrm{CP}[+$ foco]. El punto central, no seria la diferencia estructural entre (2c) y (3a), sino alguna variación en los rasgos de concordancia en el núcleo $\mathrm{C}^{\mathrm{o}}$. En síntesis, el problema teórico es explicar por qué el español europeo sólo tiene las hendidas con concordancia.

En términos discursivos, en Pinto (2008) mostré que las únicas construcciones que pueden ser utilizadas en un contexto de foco informativo son las SB. Camacho (2006) dice que las SR también son posibles en el caso de foco informativo. Las demás construcciones sólo son posibles en caso de foco contrastivo o enfático. Esa restricción se debe a la regla fonológica identificada por Zubizarreta (1998), como comenté anteriormente.

Sin embargo, en el español del Caribe, es posible utilizar una hendida básica (con concordancia) ${ }^{11}$ como ilustra el ejemplo (17) a continuación:

(17) C.E.: ¿Y hubo alguna Institución que te apoyaba en este tipo de...?

C.M.: Si, fue la Fundación Naumann, [...] la que financió mi viaje y la que ayudó a las distintas instituciones liberales de cada uno de estos países a que a su vez organizaran la

10 La diferencia entre la hendida básica y la hendida inversa seria la posición donde el foco termina la derivación: en la hendida básica, el foco estaria en la posición del especificador del $\mathrm{CP}$ subordinado y en la hendida inversa, el foco estaría en el especificador del CP matriz.

11 Ese hecho puede estar relacionado a otras propiedades del español caribeño: pérdida del pro-drop, pérdida de la inversión VS en las interrogativas etc. conforme comenta Toribio (2000). recepción y la logística del movimiento por cada uno de estos países. (PINTO, 2008, p. 87)

En síntesis, considerando exclusivamente el español europeo, se encuentran las siguientes construcciones de escisión en esa variedad: las seudo-hendidas (excepto la seudo-hendida reducida), la hendida básica con concordancia, la hendida sin cópula y la hendida inversa con marcador focal sí. La hendida básica sin concordancia y la hendida inversa con cópula no se encuentran en el español europeo.

\section{La adquisición de la escisión}

La finalidad de este artículo es presentar empíricamente cómo los niños hablantes de español europeo adquieren la esci- 
12 Analicé 17 trascripciones de BecaCESNo. Sin embargo, como este conjunto de trascripciones solo tenia 1 trascripción de niño de 2 años, añadí 1 trascripción del conjunto de Aguirre, quien analiza a un solo niño longitudinalmente.

13 En Pinto (2008, p. 104-105) muestro que el promedio de las construcciones de focalización es un $30 \%$ para cada estrategia (escisión, focalización in-situ y alteración del orden), lo que muestra que la escisión no es una estrategia preterida. Pero entre las estrategias de escisión, un $50 \%$ está representada por la seudo-hendida básica. Los demás $50 \%$ se dividen entre las otras 7 estrategias de escisión estudiadas. sión. En términos generales, me gustaría saber cuáles construcciones son las que aparecen primero. En términos específicos, en conexión con mis trabajos anteriores (PINTO, 2008; 2010), me interesa saber cuál construcción hendida básica adquieren los niños: la hendida con concordancia o la hendida sin concordancia.

No pretendo, por lo tanto, entablar una discusión teórica respecto de los procesos de adquisición del lenguaje. Por el contrario: pretendo buscar evidencias y base en los datos de los niños para el análisis que vengo proponiendo para los hechos lingüísticos de los adultos.

Para esta investigación, se analizaron entrevistas disponibles en el corpus CHILDES (http://childes.psy.cmu.edu/) con niños aprendices de español peninsular entre 2 y 10 años de edad. Se analizaron transcripciones de dos archivos/investigadores (Aguirre y BecaCESNo). Se analizó un total de 18 transcripciones ${ }^{12}$, siendo 02 trascripciones para cada edad de niños diferentes. Las grabaciones se realizaron entre 1992 y 1995.

En Pinto (2008) registré baja productividad de construcciones de escisión en el corpus analizado ${ }^{13}$. Por lo cual, se puede esperar que los datos de los niños también presentarán baja productividad. Como los documentos analizados son transcripciones de grabaciones de charla espontánea con los niños, no será sorprendiente que la escisión sea poco favorecida debido a la máxima de cuantidad "di lo justo", lo que evita que se repita la presuposición. Eso fue lo que se constató: pese a la diversidad de transcripciones analizadas, en pocas se registraron construcciones de escisión. Por otro lado, ello no significa que los niños no puedan interpretarla. Testes de compresión se hacen necesarios para averiguar el momento en que los niños comienzan a procesar tales construcciones.

\subsection{Niños de 2 años}

A los 2 años, ninguno de los dos niños presentó algún tipo de construcción de escisión. Sin embargo, un niño presentó otros tipos de construcciones de focalización:
a. MAG (Magín - 2años y 10meses)
MOT: qué quieres?
MAG: un tenedor .
MAG: yo quiero un tenedor .

b. MAG: mira lo que ha pintado .

MAG: ha pintado un [*] corazón . 
c. MOT: éstas están todas escritas xxx de papá y mamá.

FAM: toma una de aquí de Raúl .

MAG: no .

MAG: no quiero .

FAM: de ésas no, Magín .

MAG: ésta sí .

FAM: de ésas no, Magín .

MAG: ésta, ésta sí .

MAG: ésa sí quiero .

En los ejemplos (18a) y (18b), el niño produce una focalización in-situ. Obsérvese que se tiene un foco informativo y, como el objeto directo es el elemento naturalmente más a la derecha, puede recibir el acento nuclear neutro en su posición de acuerdo con las reglas de la gramática adulta. En (18c), el niño hace una inversión del orden, poniendo a la izquierda el elemento focalizado con el marcador focal "si" realizado. Teniendo en cuenta que el orden canónico del español es SVO (HERNANZ y BRUCART, 1987; ZUBIZARRETA, 1999), se puede suponer que a los 2 años y 10 meses, el niño ya haya adquirido la periferia izquierda de la oración considerando ese dato en (18c).

\subsection{Niños de 3 años ${ }^{14}$}

A los 3 años, por su vez, aparecen varios tipos de construcción de escisión:

a. SER (Sergio - 3años y 4meses)

TER: y eso los reyes te los han traido?

SER: no .

TER: no ?

SER: es una señora .

TER: una señora te los ha traido ?

SER: si .

b. SER: quién está cantando por ahí ?

TER: tu padre será .

PAD: Sergio!

SER: es Tonti \# que está cantando, estó [*] aquí !

c. CAR: quién te ha traido a ti los [/] los regalos ?

SER: ese \# es \# eh \# me ha dicho Sonia que es un guey [*] .

CAR: si es un rey .

SER: es este \# el que lleva lo [*] guegalos [*] .

14 Todos los niños siguen utilizando las otras construcciones de focalización y explicativas con "es que". 
d. TER: no la has visto ?

SER: si .

CAR: te gusta?

SER: si .

SER: es [/] es lo que más me usta [*] \# juntalo [*].

e. CLA (Clara - 3años y 7meses)

CRI: esto qué es ?

CLA: la carrosa [*].

CRI: la carroza ?

CRI: pero esto no está montado, o sí ?

CRI: ah !

CRI: que aquí va el caballo, así?

CLA: sí \# lo que pasa es que está pega(d)o .

En (19a), la entrevistadora le pregunta al niño si fueron los reyes magos los que le dieron el cinturón. El niño niega y dice que se lo dio una señora. El tipo de construcción que utiliza es una hendida truncada ${ }^{15}$, que tiene la misma estructura que la hendida básica cuya parte presupuesta está apagada. Ese hecho puede ser comprobado por el mismo niño de tres años cuando produce en (19b) una hendida básica.

En (19b), se registra el caso de una construcción hendida sin concordancia, construcción que es agramatical en la gramática adulta del español europeo de acuerdo com Moreno Cabrera (1999), por ejemplo. La pausa que aparece entre el foco y el complementizador no niega que sea una hendida básica sin concordancia porque es perfectamente posible inserir una oración parentética en ese ambiente; por ejemplo, "es Tonti, según María, quien está cantando" ${ }^{\prime 16}$.

En el ejemplo (19c), pasa lo mismo que en el ejemplo (19b) a diferencia de que el niño produce una hendida con concordancia.

En (19d), el niño produce una construcción anómala, en la

15 La hendida truncada es una construcción de escisión en la que se borra la presuposición y se realiza únicamente la copula focalizadora y el elemento focalizado.

16 La posibilidad de inserir una oración parentética y otros tipos de elementos entre el foco y el complementador lleva a Ribeiro (2009) a postular que la relación entre foco y complementador no es una relación Spec-Head. Para Ribeiro (2009) el complementador estaría en una posición más baja, como FinP. 
(20) a. JOR (Jorge - 4años y 4meses)

JUA: ala \# que asco, con mostaza !

DAV: te da asco la mostaza?

JUA: a mi no me gusta .

JOR: a mi me apesta \#\# espero que no tenga

lechuga .

DAV: mira que sois guarros \# macho .

JOR: es Juan .

b. GAB (Gabriel - 4años y 4meses)

DAV: que yo no la he visto .

GAB: eh?

DAV: yo no he visto la película?

GAB: pues \# mira \# lo que ha pasa(d)o \# <es

que $>$ /] es que hay $x x x$.

\subsection{Niños de 5 años}

A los 5 años, los niños producen algunas construcciones de escisión:

(21) a. CAR (Carmen - 5años y 7meses)

EST: si \# cuentame el cuento .

CAR: cual?

CAR: de aladino $o+/ /$.

EST: el de Aladino \# es que yo no he visto la película .

CAR: es así como muy varia \# ados [?] largo .

EST: es muy largo ?

CAR: y todas las cosas y Aladino no me las sé pero \# las repaso \# lo que sí me sé es media canción .

b. PAT (Patrícia - 5años y 8meses)

AUN: y eso(s) carrito(s) habia que paga(r) a que sí para montar?

PAT: no, no había que pagar .

AUN: no?

PAT: lo que pasa (es) que habia una cola \# y mira hemos montado en un tren que corría muchísimo muchísimo muchísimo...

c. PAT: (cantando la canción)

AUN: esta muy bien!

PAT: asi es como me la ha enseña(d)o una amiga mia pero dice Reme(dios) que es así +" /. 
En (21a) y (21b), ellas producen una seudo-hendida básica. También se encuentra un ejemplo de seudo-hendida invertida, como ilustrado en (21c).

\subsection{Niños de 6 años}

Una niña de 6 años produjo algunas construcciones de escisión ${ }^{17}$ :

(22) a. SAN (Sandra - 6años y 6meses)

SAN: además que una niña \# sería su padre el que repartía los premios \#

porque ella se salió del dibujo y encima le dan un premio .

b. SAN: ay \# no lo pongas ahí \# que es donde tengo que echar esto !

c. SAN: yo le digo a mi madre que él sí que se tiene que cortar el pelo.

d. RAQ: y no te gusta Emilio Aragón ?

SAN: sí .

RAQ: también \# y Lidia?

SAN: mi madre sí que la ha visto .

En (22a), la niña produce una hendida básica con concordancia o seudo-hendida extrapuesta. En (22b), la niña produce una seudo-hendida invertida, cuyo elemento focalizado es un pronombre relativo. En (22c) y (22d), la niña produce una hendida invertida con la partícula "sí" en el lugar de la cópula.

Es interesante observar la ocurrencia de hendidas invertidas, aunque no sean las verdaderas hendidas con la cópula, ya que Moreno Cabrera (1999) y Pinto (2008) no las registran en el español europeo adulto.

\subsection{Niños de 7 años}

Sólo encontré dos construcciones de escisión en las niñas de 7 años, una seudo-hendida invertida (23a) y una seudo-hendida básica (23b):

17 En la transcripción de MAI (9 años) participa de la charla su hermano de 6 años. Y ese chico produce las mismas construcciones que las presentadas por los niños de 6 años bajo análisis. a. PAU (Paula - 7años y 5meses)

INV: es el malo de la película?

PAU: si .

INV: y éste ?

PAU: su padre \# el padre de Yasmin .

INV: es bueno?

PAU: si .

PAU: esto ya es lo que te decía . 
b. PAU: y lo que me daba más miedo lo de las < gadriografías $>[*]$ era que

Me pinchaban en la cabeza .

\subsection{Niños de 8 años ${ }^{18}$}

La niñas de 8 años produjeron construcciones seudo-hendidas básicas (24a) y (24g); seudo-hendidas invertidas (24a) y (24d); hendidas básicas con concordancia (24c) y (24f); hendida invertida (24e).

(24) a. ANA (Ana - 8años y 2meses)

ANA: muchas veces se lo digo que se lo voy a decir y lo que hago es decir se

lo explico muy bien y entonces ella no lo puede hacer \# es la mayoría .

b. ANA:

éste es el que he hecho que todavía no se ha secado [ $[$ ! señalando $]$.

c. ANA: sí \# yo soy profesora de las demás \# mira \# como somos cinco pués yo

soy una y sé escalar \# y a otro que tiene miedo de las alturas le he

conseguido que escalara \# mira \# está por ahí [= ! señalando] \# hay

unas tierras y por allí al fondo \# y escalamos por ahí .

ANA: primero soy yo la que me meto y digo \# por aquí se puede andar y

por aquí no se puede andar \# y si no se puede andar me invento modos

para andar.

d. VIR (Virginia - 8años y 9meses)

VIR: eso es lo que más me gusta .

e. MAR: pero hace mucho que no sacan ningún disco \# no \# Mecano?

VIR:

yo es que ahora los veo muy poco, tengo una camiseta de Mecano .

${ }^{18}$ Las niñas de 8 años son las que más producen construcciones de escisión.

MAR: es que no se les ve, nada [/] nada . VIR: yo ej $\left[{ }^{*}\right]$ que ahora les veo más poco $+/ /$. $(e j=e s)$ 
f. VIR: por ejemplo \# estamos jugando y a lo mejor soy yo la que empiezo .

g. VIR: ento (nce) s a mi ya no voy a ir a volver nunca más a esa piscina .

VIR: porque luego la que está bien es la del Burgo .

VIR, la niña de 8 años, también produce una hendida invertida (24e), construcción que no se registra en la producción de los adultos.

\subsection{Niños de 9 años}

Las niñas de 9 años, siguen produciendo las seudo-hendidas básicas (25a) y (25b). En estos ejemplos, las niñas producen seudo-hendidas más complejas: (25a) ilustra una seudo-hendida de una perífrasis verbal (tener que + verbo) y (25) representa una seudo-hendida con un tiempo compuesto (en general, sólo se encontraron seudo-hendidas con la cópula en el tiempo presente). En (25d), se encuentra un ejemplo de seudo-hendida invertida con pronombre relativo. En (25c) y (25e) se encuentran construcciones hendidas invertidas con el marcador focal "si" y con la cópula respectivamente:

(25) a. EST (Esther - 9años y 1mes)

EST: entonces lo que tienes que hacer es que la juntas y luego la dejas secar

b. EST: y entonces hoy lo que hemos hecho ha sido pintarla.

c. EST: entonces se van a la piscina y ven todo lo que sucede y dice la madre: tú si que serías un buen padre .

d. MAI (Maria Del Carmen - 9años y 11meses)

MAI: y han dicho por la tele(visión) que van a quitar \# en vez de los dibujos

violentos \# que es lo que tenían que quitar \# y las peli(cula)s violentas

\# van a quitar los juguetes violentos \# las espadas \# los cuchillos \# bueno

\# todo eso violento \# pero de juguetes \# claro \# y mi hermano tiene un

montón así de ésos [= juguetes violentos] . 
e. $\quad R A Q$ (Raquel - 9años y llmeses. Hermana de MAI) RAQ: como mi hermana bien ha dicho antes \# en el colegio se burlan mucho de las gafas y a mí eso me molesta mucho \# porque yo antes llevé gafas .

RAQ: me las quitaron por medio de una operación . RAQ:

la operación fue que me hicieron en el ojo $+/ /$.

\subsection{Niños de 10 años}

Por fin, las niñas de 10 años producen seudo-hendidas básicas, como ilustrado en los ejemplos (26a) y (26b), y hendidas invertidas como en (26c) y (26d):

(26) CRI (Cristina-10años y 2meses)

a. CRI: yo soy una niña que me llevo muy bien con las amigas .

CRI: pero lo que pasa es que hay una que no me cae bien y otras sí.

b. TAM (Tâmara - 10años y 3meses)

ANA: y qué es lo que más te gustó de lo que te regalaron?

TAM: pues \# lo que más me gustó \# fue <lo de> [/ lo del Ken porque

[//] vamos en realidad me gustó todo

pero lo que más más más del todo era la cinta luego el Ken y luego lo demás .

c. TAM: <es que como mi familia es tan dormilona> $V / /$ yo es que por la noche el dia de Reyes no puedo dormir .

d. TAM: fuimos el día que \# una oveja iba a parir y entonces pues \# .

TAM: y estuvimos ordeñando una vaca .

TAM: yo es que al principio creía que era muy difícil , no?

TAM: pues al poner la mano y hacer así , que fácil!

TAM: me salió a la primera \# !

\subsection{Algunas consideraciones sobre los datos}

Los datos mostraron que, a pesar de que no hayan producido construcciones de escisión, los niños de dos años han adquirido ya la periferia izquierda de la oración. La escisión comienza a aparecer 
a partir de los 3 años de edad. Las primeras construcciones que aparecen son las tres hendidas básicas (truncada, con concordancia y sin concordancia - reacuérdese que, por el análisis de PINTO, 2008, 2010, las tres construcciones tienen la misma estructura) y la seudohendida básica. Sin embargo, la hendida básica sin concordancia sólo aparece en el corpus analizado en un niño de 3 años de edad. Se observó que las seudo-hendidas aparecen desde los niños de 3 años hasta los niños de 10 años. Los niños de 6, 8, 9 y 10 años producen construcciones hendidas invertidas. No se registró en el corpus ningún caso de hendida sin cópula ni de seudo-hendida reducida.

Lo interesante es observar que, aunque una serie de estudios sobre la escisión en el español europeo (MORENO CABRERA, 1999; DI TULLIO, 2005; PINTO, 2008) muestra que las hendidas no forman parte de esa variedad lingüística, se encontraron diversas ocurrencias de hendidas inversas (la hendida básica sin concordancia sólo aparece en el niño de 3 años), inclusive en el habla de los adultos, como muestran los ejemplos en (27):

(27) a. JUA: yo ya he termina(d)o .

SON: tú ya has terminado?

SON: qué rapidez \# tú es que tienes una boca muy pequeña me parece a mí, eh Jorge?

b. JUA: Pues anda \# que me como unos bocadillos así .

JOR: yo así .

SON:

sí?

JUA: ala \# yo treinta barras \# entonces al día!

SON: y tú?

JOR: yo?

JOR: ochocientas mil .

JUA: pero tú es que lo haces en ochocientos años .

c. CAR: sí \# una señora \# tendiendo a los niños del pie \# para que se sequen .

NAT: para que se sequen?

CAR: porque no se ponen el abrigo \# y se mojan \# con la lluvia .

NAT: claro \# como tú te pones el abrigo $+/$.

CAR: como son niños pequeños no lo entienden .

CAR: y lo que nunca $<$ han sido a mamas $>$ [?] \#

$<\mathrm{Xxx}$ en tonterías $>[=$ ! riendo $]$

NAT: tú es que ya lo entiendes .

CAR: claro \# ya lo entiendo .

En (27), los participantes (el niño - JOR, su hermano - JUA y la investigara - SON) están merendando y el hermano de Jorge 
termina de comer su hamburguesa. La investigadora le dice a Jorge que él tiene la boca muy pequeña. Según muestra el contexto, la investigadora quiere decir que no fue Juan quien comió demasiado rápido, pero Jorge es el que tiene la boca pequeña, y por eso todavía no había terminado. Eso deja claro que hay un foco contrastivo en el "tú" de la frase destacada en el ejemplo (27a). Sucede más o menos lo mismo en la continuación del diálogo en (27b); pero es el niño hermano de Jorge quien la dice. No se computó, sin embargo el dato en (27b) entre la producción infantil porque no hay informaciones sobre la edad de Juan.

En (27c), la niña (CAR - Carmen) de 5 años está diciendo que sus compañeros de clase no entienden que tienen que ponerse el abrigo para salir a la lluvia. El contraste aparece porque, aunque Carmen tenga la misma edad de los chicos, ella sí ya entiende que debe ponerse el abrigo para salir a la lluvia.

El que aparezcan hendidas inversas en el habla adulta espontánea indica que: a) como señaló Di Tullio (1999), parece que actúa algún factor normativo ya que no se registran en el patrón europeo, pero se registran en el habla espontánea; b) puede haber algún tipo de variación dialectal en el español europeo mismo ya que no hay especificación en las transcripciones de dónde se grabaron las charlas con los niños.

\section{Consideraciones finales}

El problema que levanté se refería a la tipología de la escisión adquirida por los niños españoles. Teniendo en cuenta que la adquisición del lenguaje (de sintaxis, por lo menos) puede ser entendida como la fijación de parámetros a partir de la relación entre los principios de la facultad del lenguaje y el input que el niño recibe, como ilustrado en (28),

(28) input Lengua X ------> facultad del lenguaje -----> fijación de parámetros Lengua $X$

fue posible cuestionar, a partir de lo que se sabe sobre la historia y variación de la escisión en el español, si los niños adquirían más tipos de construcciones y luego los perdían llegando a la gramática adulta o sólo adquirían los tipos de la gramática adulta $^{19}$.

Los datos mostraron que (a) parece que la escisión en el español peninsular no se comporta como dicen los textos sobre el tema y que (b) los niños producen más tipos de construcciones

Sérgio Menuzzi comenta que seria importante explicar por que los niños probarían más construcciones de lo que escuchan en el input. En este momento, sin embargo, no tengo ninguna respuesta para esta cuestión. de escisión que la gramática adulta según las referencias indicadas a lo largo del texto.

Las seudo-hendidas no pusieron ningún problema para el estudio del tema ya que se presentan de la misma manera tanto en la gramática adulta como en la gramática infantil. Ya las construcciones hendidas, principalmente las hendidas básicas, sí imponen un problema para el tema. 
Sobre la diferencia estructural entre las hendidas básicas e invertidas, Kato y Ribeiro (2009) proponen que sean las construcciones presentativas las que dan origen a las hendidas inversas y no las hendidas básicas:

(29) a. O meu pé é que dói. (hendida inversa)

b. É que o meu pé dói. (presentativa) (KATO y RIBEIRO, 2009, p. 137)

La propuesta es que ambas construcciones en (29) tengan un complementizador $\mathrm{C}^{\circ}$ como los que completan verbos como "decir" y "pensar". Como este CP no tiene rasgos de foco, la derivación converge de dos maneras posibles: en el caso de la presentativa, ambos sintagma nominal "o meu pé" y complementizador "que" tienen el rasgo [-foco] y movimientos adicionales no se hacen necesarios: el sintagma nominal permanece dentro del IP subordinado al complementizador "que". En el caso de la hendida inversa, el sintagma nominal con el rasgo [+foco] se desplaza de su posición en la oración subordinada para el CP matriz ya que el $\mathrm{CP}$ subordinado no tiene los rasgos compatibles. Por otro lado, a diferencia de las presentativas o hendidas inversas, las hendidas básicas tendrían un CP subordinado con rasgos [+foco].

Respecto de las hendidas básicas, como sólo un niño de 3 años produjo la construcción sin concordancia (la que no se registra en la gramática adulta), se puede suponer que, de hecho, es excluida por un proceso natural de fijación de parámetros. Es decir, los niños comienzan su proceso de adquisición con las dos posibilidades, como una gramática como la del portugués de Brasil, y, en algún momento, aprende que tiene que hacer la concordancia en el CP subordinado en vez de emplear el "que" sin concordancia por defecto. Sornicola (1988), Prince (1979) entre otros, estudian las diferencias sintácticas y discursivas de las hendidas (it-clefts) y seudo-hendidas (wh-clefts) y, en estos trabajos, ambas construcciones "It is John that sings" $\mathrm{y}$ "It is John who sings" ("Es Juan que canta" y "Es Juan quien canta" respectivamente) son analizadas como it-clefts. Sornicola (1988) estudia la escisión en diversas lenguas y dice que las lenguas semíticas (árabe y hebreo, por ejemplo) no tienen las it-clefts. Sin embargo, si ambos tipos de hendidas tienen la misma estructura y los mismos pasos en la derivación, ¿por qué sólo una es gramatical en el español adulto? Todavía no tengo una respuesta para esa cuestión.

El problema de las hendidas invertidas, por otro lado, puede ser explicado a partir del desajuste entre normativa y vernáculo: como la mayoría de los estudios del español se basan en datos de la norma culta, que sufre mucha presión del patrón (sobre este tema, ver a PINTO, 2009), tales estudios no registran tales construcciones ya que las condena la normativa española ${ }^{20}$. 
20 Tanto el estudio de Pinto (2008) como el presente estudio estuvieron basados en datos de corpus. Posiblemente, Pinto (2008) no encontró hendidas invertidas debido al hecho de que su corpus fue de lengua escrita y controlada (los guiones). Por otro lado, el corpus utilizado en la presente investigación es de lengua espontánea y hablada con niños, donde no se espera que haya mucha presión de la normativa.

${ }^{21}$ Como mencioné antes, parece que en España hay variación en la escisión. Registré en diversas ocasiones en Barcelona casos de hendidas básicas sin concordancia:

¡Ah!, ya sé qué pasa... Eso fue Andréa que lo rompió. yo.

Es algo así que te digo

Parece que tú seas serio y a partir del próximo mes es contigo que yo hablo.

Los ejemplos (i) y (ii) fueron producidos por hablantes diferentes y en contextos diferen tes. El ejemplo (iii) es un habla de la película "Una casa de locos" (cuyo título en portugués es "Albergue español") que está grabada en Barcelona. El ejemplo se refiere al habla de un catalán.

22 Este hecho será así si no se comprueba que los niños de diferentes clases sociales no están expuestos de hecho a gramáticas diferentes. Por ejemplo, en el caso del portugués de Brasil, aunque haya marcas fonéticas, prosódicas, semánticas y léxicas que distinguen clases sociales, hay muchos aspectos sintácticos condenados por la normativa que son compartidos por hablantes escolarizados y no escolarizados. Para mencionar solamente algunos, se puede indicar la próclisis categórica y el uso de formas nominativas en el lugar de sus equivalentes acusativas.
Lo que dice Di Tullio (1999, p. 6) sobre la normativa y las hendidas (cf la nota 5) queda evidente cuando se considera lo que dice Gómez Torrego (2002, p. 277):

En las estructuras u oraciones ecuacionales, cuando el componente que no es la oración de relativo lleva preposición, ésta debe mantenerse en el componente u oración de relativo, al menos según la norma culta del español de España. Ejemplo:

*Fue por Juan que me enteré de lo sucedido (se dice: fue por Juan por el que (quien) me enteré...).

Tampoco se consideran correctas las oraciones ecuacionales formadas con adverbios interrogativos y un relativo que. Sin embargo, son relativamente frecuentes en Hispanoamérica. Ejemplos:

*¿Cuándo fue que viniste? (en España se dice: ¿cuándo viniste?)

*Cómo fue que lo hiciste? (en España se dice: ¿cómo lo hiciste?)

Tampoco pertenecen a la norma culta del español de España las estructuras ecuacionales en que aparece un que en vez de un adverbio. Ejemplo:

*Ayer fue que vino (en España se dice: ayer fue cuando vino).

Frente a esos hechos, hay explicar, en trabajos futuros, lo que, de hecho, pasa con las hendidas básicas en el español europeo: si su ausencia se debe, de hecho, a una cuestión de adquisición de primera lengua o a una cuestión de escolarización ${ }^{21}$. En el caso de que el problema sea de escolarización, una investigación sociolingüística aclararía la cuestión: si se analizan diversos niveles sociales (escolarizados $X$ no escolarizados; rurales $X$ urbanos etc) y se detecta variación respecto del fenómeno (por ejemplo, si los adultos escolarizados sólo usan la variante quien y los no escolarizados utilizan ambas variantes que y quien que aparecen en la adquisición), la cuestión puede ser de escolarización ${ }^{22}$. Por otro lado, si las hendidas canónicas sin concordancia no aparecen, de hecho, en la edad adulta en todos los niveles socio-educacionales (guardadas, obviamente, las observaciones de que es posible la existencia de diversas gramáticas en el mismo español europeo), se deberá "contar alguna historia" para explicar por qué las cosas son así.

\section{Resumo}

Considerando a variação da clivagem no espanhol atual, este trabalho pretende averiguar como as crianças espanholas adquirem essas construções tendo como pergunta central se as crianças espanholas 
produzem inicialmente as construções inexistentes na variedade européia adulta e em seguida as perdem ou se as crianças nunca produzem essas construções. O estudo analisou 18 crianças, entre 2 e 10 anos de idade (2 crianças de cada faixa etária) a partir do corpus CHILDES. Os dados mostraram que as crianças produzem construções inexistentes na gramática adulta, sendo que uma delas só aparece na criança de 3 anos e outra permanece em todas as faixas etárias. A interpretação dos dados é a de que não há, em princípio, um problema de aquisição da linguagem, mas de variação do espanhol europeu já que as construções consideradas inexistentes em diversos estudos são encontradas na fala dos adultos na interação com as crianças.

Palavras-chave: Clivagem; variação do espanhol; sintaxe do espanhol europeu.

\section{REFERENCIAS}

CAMACHO, José. In situ focus in Caribbean Spanish: towards a unified account of focus. En: SAGARRA, Nuria; TORIBIO, Almeida Jacqueline (Eds.). Selected Proceedings of the 9th Hispanic Linguistics Symposium. Somerville: Cascadilla Press, 2006, p. 13-23. DI TULLIO, Ángela. Clefting in spoken discourse. En: Encylopedia of Language of Linguistics. 2. ed. Universidade de Oxford, 2005.

. Hendidas, inferenciales y presentativas. En: DÉNIZ, M. T.; SAMPER PADILLA, J. A. (Eds.). Actas del XI Congreso Internacional de la Asociación de Lingüística y Filología de la América Latina. v. 1, 1999, p. 511-520.

GÓMEZ TORREGO, Leonardo. Gramática didáctica del español. 8. ed. Madrid: Ediciones SM, 2002.

HERNANZ, María Lluisa; BRUCART, José María. La sintaxis. Princípios teóricos. La oración simple. Barcelona: Crítica, 1987.

KATO, Mary. Aquisição e aprendizagem: de um saber inconsciente para um saber metalingüístico. En: GRIM-CABRAL, L.; MORAES, L. (Eds.). Investigações a linguagem: ensaios em homenagem a Leonor Scliar-Cabral. Florianópolis: Mulher, 1999, p. 201-225.

KATO, Mary; RIBEIRO, Ilza. Cleft sentences from Old Portuguese to Modern Portuguese. en: A. Duffer y D. Jakob (Eds.). Focus and background in romance languages. London: John Benjamins, 2009, p. 123-154. 
MODESTO, Marcelo. As construções clivadas no português do Brasil: relações entre interpretação focal, movimento sintático e prosodia. São Paulo: Humanitas, 2001.

MORENO CABRERA, Juan Carlos. Las funciones informativas: las perífrasis de relativo y otras construcciones perifrásticas. En: BOSQUE, Ignácio; DEMONTE, Violeta (eds.). Gramática descriptiva de la lengua española. v. 3. Madrid: Espasa Calpe, 1999, p. 4245-4302. PAGOTTO, Emílio G.. Norma e condescendência; ciência e pureza, Lingua e Instrumentos Lingüisticos, v. 2, p. 49-68, 1998.

PINTO, Carlos Felipe da C.. A variação das construções de clivagem no espanhol atual, Revista do SELL, vol 2, n. 1, p. 1-23, 2010.

. Los criterios sintácticos en la división dialectal del español. En: PINTO, Carlos Felipe; IRALA, Valesca Brasil (Eds.). Um dossiê de estudos lingüísticos hispânicos. São Paulo: Casa do Novo Autor, 2009, p. 61-96.

. Uma análise das construções de clivagem e outras construções focalizadoras no espanhol atual. Dissertação (Mestrado em Letras), Universidade Federal da Bahia, 2008.

PRINCE, Ellen. A comparison of wh-clefts and it-clefts in discourse, Language, v. 54, p. 883-906, 1978.

RIZZI, Luigi. Residual verb second and the Wh criterion, Techinical Reports in Formal and Computational Linguistics. v. 2, 1991.

RIBEIRO, Ilza. Construções de focalização. Comentários ao texto de Simone Guesser. En: ENCONTRO DOGT DE TEORIA DA GRAMÁTICA - ANPOLL, Brasília: UnB, 26 e 27 de novembro de 2009.

SORNICOLA, Rosanna. "It-clefts and wh-clefts: two awkward sentence types". Journal of Linguistic, v. 24, p. 348-79, 1988.

TORIBIO, Almeida Jacqueline. Setting parametric limits on dialectal variation in Spanish, Lingua, v. 10, p. 315-341, 2000.

ZUBIZARRETA, María Luisa. Las funciones informativas: tema y foco. En: BOSQUE, Ignácio; DEMONTE, Violeta (eds.). Gramática descriptiva de la lengua española. v. 3. Madrid: Espasa Calpe, 1999, p. 4215-4244.

Press, 1998.

Prosody, focus, and word order. Cambridge, Mass: The MIT 